\title{
Public Health Interventions to Combat Micronutrient Deficiencies
}

\author{
Gail G. Harrison, $\mathrm{PhD}^{1}$
}

\begin{abstract}
Micronutrient deficiency conditions are global in scope, with developing countries suffering most from such "silent epidemics". There are several different approaches to combating micronutrient malnutrition at the level of populations and vulnerable groups. We review these briefly with attention to successes, advantages and disadvantages. We recommend active governmental leadership and policy review on a continuing basis to address these fundamental public health problems.
\end{abstract}

Key Words: micronutrients, malnutrition, Public Health, interventions, fortification, supplementation, nutrition monitoring

\section{INTRODUCTION: THE IMPORTANCE OF ACTION}

Micronutrient deficiencies rank among the top twenty risk factors for morbidity and impaired quality of life worldwide, with particular burdens falling on populations in poor countries, on children, and in the case of iron deficiency, on women of childbearing age. ${ }^{1}$ Amelioration of these deficiencies is among the most cost-effective of public health interventions in improving overall health, the outcomes of common infectious diseases, and quality of life. ${ }^{2,3}$

There are a number of approaches that have been utilized at different times and in different populations, most often in attempts to deliver single nutrients known to be limiting for a population, but increasingly with attention to multiple micronutrients and to integrated public health programs. The reader is referred to the most comprehensive review to date of interventions to improve nutrition with a focus on maternal and child nutrition, namely that of Bhutta et al. ${ }^{4}$ (2008 Lancet Series on Maternal and Child

\footnotetext{
${ }^{1}$ Professor, UCLA School of Public Health; Director, UCLA Center for Global and Immigrant Health; Senior Research Scientist, UCLA Center for Health Policy Research; Associate Director, Program for Healthy and At-Risk Populations, Division of Cancer Prevention and Control, UCLA/Jonsson Comprehensive Cancer Center.
}

Correspondence: Gail Harrison at email gailh@ucla.edu 
Undernutrition). The present review will mention several of these approaches, followed by attention to the successes of integrated programs.

\section{EDUCATION AND DIETARY DIVERSIFICATION}

While information and education are clearly valuable and valued among populations at nutritional risk, there are few instances of documented substantial impact from this approach alone. The chances of success are good only when there are no other serious constraining factors in terms of access to foods, when the target audience is motivated and when the educational intervention is well designed and delivered. The major advantage to education and behavior change is sustainability. By definition, any changes in knowledge and practices will be within the economic and social capabilities of the target audience and transmissible to the next generation. This makes it possible to address multiple nutrient deficiencies simultaneously without risk of antagonistic interactions. There is some evidence that in relatively advantaged populations, targeted educational approaches can work well. 5,6

In the context of more impoverished environments, there is a growing literature supporting home- and food-based approaches to improve micronutrient status, as recently reviewed by Gibson and Anderson. ${ }^{7}$ The approaches they review focus on improvement of dietary zinc availability through encouragement of home production and use of animal source foods and home food processing strategies such as germination and fermentation to improve mineral availability. Their review provides an example of a successful dietary diversification/modification program developed and implemented in West Africa by Helen Keller International, along with consideration of requirements for scaling up such programs.

\section{ECONOMIC GROWTH, POVERTY ERADICATION AND MICRONUTRIENT MALNUTRITION}

Since the root cause of most malnutrition is poverty, there is always a policy-related argument that if economic growth can be achieved in poor countries, diets will improve with increased incomes and will preempt the need for additional public health interventions. While there is some basis for this argument, the weight of evidence points to a need for additional nutritional "safety nets." There is wide but not universal agreement that the virtual disappearance of iodine, niacin and other micronutrient deficiencies 
(excepting iron) in the period surrounding and following the Second World War was a combination of economic recovery after the Great Depression and of fortification of staple grains with micronutrients and of salt with iodine. ${ }^{8}$

However, the occurrence of economic shocks demonstrably set back progress against malnutrition in Southeast Asia in the late 1990s. The recent (2008) economic crisis has by recent estimates added several hundred million to the count of the world's malnourished within a very short period of time. ${ }^{9}$ Even if it were more predictable, general economic growth is a lagging predictor of nutritional improvement. Alderman and Linnemayr ${ }^{10}$ have recently modeled, using a large data set based on Demographic and Health Surveys in a number of countries, the impact of economic growth on anemia. They found that anemia rates do decrease as incomes increase, but that the response is "anemic" at best, with anemia rates declining roughly one-fourth as rapidly as income increases and only at half the speed that rates of childhood underweight decline. They conclude that reliance on economic growth to solve the problem of iron deficiency will not work, and that efforts need to be redoubled to find and implement safe and effective methods of iron supplementation and fortification.

\section{SUPPLEMENTATION}

Direct supplementation of vulnerable subpopulations with micronutrients, usually through a primary healthcare system or healthcare delivery system such as an immunization program, has been shown to be effective and very cost-effective for young children for vitamin A and for zinc., ${ }^{1,2}$ Supplementation for pregnant women with iron and folic acid has had more uneven results, likely at least in part because of poor compliance due to side effects of the supplements. A direct supplementation approach through a healthcare delivery system has the advantage of directly reaching portions of the population most at risk while not putting other segments of the population at risk of overconsumption or adverse interactions. The long-term disadvantages, however, are obvious and relate primarily to sustainability, coverage and compliance.

Supplementation depends upon a viable delivery system with built-in quality control, as well as upon wide coverage and high take-up rates among vulnerable individuals and families. Supplementation only works if the supplements are available and accessible and the intended individuals actually take them. Recently, much attention has been devoted to using multiple micronutrient supplementations, rather than the traditional iron and folic acid only, for pregnant women; in some cases, significant 
advantages have been seen. The best outcomes have been seen when the supplementation is coupled with community-based health facilitators' interventions, ${ }^{11}$ arguing for more integrated, less vertical approaches.

Supplements for institution based elderly and other institution based population groups such as long-term mental hospital patients or others in long-term care or custody should be considered as part of the nutritionrelated responsibilities of public health authorities.

\section{FORTIFICATION}

Micronutrient fortification of widely consumed basic foods is a public health approach that has been widely used and continues to evolve. Fortification of foods can be conceptualized as central (with micronutrients added in commercial or other central processing, prior to distribution or marketing), or peripheral (involving the addition of micronutrient substances to foods at the household or other consumption level). Centrally handled fortification may be applied to food vehicles essentially universally consumed by the population (notable examples have been grain flours, salt, sugar, monosodium glutamate) or to specific food products designed to be consumed by vulnerable target groups. An example of the latter is the hugely successful fortified gruel for toddlers marketed throughout Central America, INCAPARINA, which was developed as a fortified version of a traditional and staple infant/young child food product in the given culture. A very recent example of this approach is a successful, large-scale trial of distribution of iron-fortified milk in reducing iron-deficiency anemia among low-income children in Mexico. ${ }^{12}$

Vitamin D fortification of milk practiced during World War II, then suspended, has been mandatory in Canada since 1979 and has been almost universally practiced in the United States since the 1940s. Since 1998, fortification of flour has been practiced in Canada and the United States, Chile and most of the countries in the Americas to prevent birth defects (neural tube defects), ${ }^{13}$ and is recommended by WHO. ${ }^{14}$

The advantage to fortification of food items consumed by the general population, provided that safe and effective levels of the relevant nutrients can be delivered through an appropriate food vehicle, is that no or minimal behavior change is required on the part of the population. This provides a tremendous advantage in terms of coverage and efficiency. The approach demands that the food vehicle be purchased or otherwise distributed essentially universally; thus in some areas where the rural poor depend primarily on subsistence agriculture, coverage may be suboptimal. Fortification of staple 
foods requires active governmental leadership, policy and political will based on sound scientific evidence; the policy process has proved to be a complex stumbling block in some situations. For example, although more than fifty countries have implemented fortification of flour with folic acid, no country in Europe has done so and the European approach remains to recommend supplementation for women at risk of pregnancy.

Fortification at the periphery has been utilized as an approach to deliver micronutrient fortificants to particular at-risk groups such as young children or school children. A number of products have been developed including fortified blended foods (such as INCAPARINA), complementary food supplements such as the fortified nut butter developed for home fortification, ${ }^{15}$ and micronutrient powders designed to be added to food at the point of consumption. Generally positive results have been found in a number of controlled trials for such products. For example, a randomized trial of adding an iron- and riboflavin-rich powder to school meals in India reduced anemia in five to nine year old children by more than fifty percent, as well as essentially eliminating clinical signs of riboflavin deficiency. ${ }^{16}$ The currently available and tested products have recently been reviewed in detail by the Maternal, Infant and Young Child Nutrition Working Group. ${ }^{17}$

\section{INTEGRATED APPROACHES}

Public health approaches to improving nutritional status in vulnerable groups have been most successful, particularly in large populations with significant income, health and nutrition disparities, in the context of integrated programs. We will briefly mention three types of integrated approaches: 1) targeted maternal and child nutrition programs, using the example of the Special Supplemental Nutrition Program for Women, Infants and Children (WIC) in the US; 2) the Essential Nutrition Actions (ENA) approach; and 3) conditional cash transfer (CCT) programs with health and nutrition components, which are widely utilized now in Latin America and for which the Mexican program, Oportunidades, serves as the best-evaluated model. While these types of programs offer efficiency, wide coverage, and potential for major health improvements in populations, they are expensive and they have proved difficult to evaluate precisely because of their wide coverage.

Targeted, integrated maternal and child nutrition programs are exemplified globally by the work of the Ten-Year Strategy for Integrating Maternal, Infant and Young Child Nutrition, summarized recently by Zehner. ${ }^{18}$ However, lessons must also be learned from long-standing successful 
programs addressing nutritional inequities in more developed countries as well.

Women, Infants and Children: The Special Supplemental Nutrition Program for Women, Infants and Children in the United States is one of the longest-standing, largest and most durable integrated maternal, infant and child nutrition programs. Begun in the 1970s, this is a federal assistance program of the Food and Nutrition Service (FNS) of the United States Department of Agriculture (USDA) for healthcare and nutrition of lowincome pregnant women, breastfeeding women, and infants and children under the age of five.

WIC now reaches more than half of all pregnant women and infants born in the US and almost all of those residing in households whose income is below the federal poverty level. The program was designed to be tightly targeted to those most at nutritional risk during vulnerable developmental periods: pregnancy, lactation, infancy and early childhood. Eligibility requires a per-capita household income less than $185 \%$ of the federal poverty level plus documented nutritional or medical risk factors for poor nutrition or indications of nutritional compromise such as anemia, underweight, or low birth weight. Participation is certified in six-month intervals, maintaining tight targeting. An integrated package of benefits is delivered, including nutrition education, health and social service referrals, breastfeeding promotion and support, and a prescribed set of supplemental foods designed to be nutrient-dense and to address the nutrients most likely to be low in the diets of the eligible population.

The WIC program very recently went through the first major revision in the content of the supplemental foods provided to make them consistent with the Dietary Guidelines for Americans, which are revised every five years and for the policy framework for all US federal food-related programs. ${ }^{19}$ WIC has undergone many evaluations, consistently showing positive effects on dietary quality, health outcomes (e.g., birth weight, anemia), and health service utilization. ${ }^{20-22}$ Rigorous evaluations are difficult, however, because of the program's wide coverage and the fact that eligible non-participants are necessarily (and unobservably) different from participants.

\section{THE ESSENTIAL NUTRITION ACTIONS (ENA) APPROACH}

The ENA framework, now being adopted by several large countries, grew out of the 2003 Lancet child survival series in which a set of preventive nutrition interventions were identified to reduce child mortality. ${ }^{23}$ The ENA framework (originally called the "Minimum Nutrition Package") was 
developed by WHO, UNICEF, and the U.S. Agency for International Development and focuses on specific nutrition messages and support at critical points during pregnancy and the first two years of life, using multilevel health sector and community channels for program implementation.

Support for exclusive breastfeeding, vitamin A and zinc supplementation, appropriate complementary feeding starting at six months, and nutritionrelated health practices including delayed umbilical cord clamping, utilization of trained birth attendants, maternal dietary evaluation and counseling, and immunization are integrated in country-specific program designs. That such programs make a difference is now being demonstrated clearly in some of the poorest countries (e.g., Madagascar ${ }^{24}$ ). Implementation and evaluation of these programs has depended on external funding, raising the question of sustainability, but improvements in health services and general community involvement hold promise for long-term benefit.

\section{CONDITIONAL CASH TRANSFER PROGRAMS WITH NUTRITION AS THE CENTRAL OBJECTIVE}

Cash transfers offer a final model for integrated programs affecting micronutrient deficiencies as well as other health and nutrition outcomes. These programs have become widespread in Latin America as a more or less standard model for poverty reduction and for buffering children and families against the negative nutritional and health effects of poverty. The basic conceptual framework is that cash payments are made to poor families to supplement low incomes, conditional on the families fulfilling specific behavioral expectations, usually including school attendance for appropriately aged children and use of preventive healthcare services, and in some cases supportive treatment or rehabilitation of malnourished children.

A recent systematic review of CCTs on health outcomes and use of health services provided strong evidence of positive impacts on nutritional status and health outcomes as well as use of health services. ${ }^{25}$ Two of the largest CCTs are those in Mexico (Oportunidades, originally named Progresa) and the Brazilian Bolsa Familia Programme. The Brazilian program has had less thorough evaluation than the Mexican one, but in general has shown positive effects on education and poverty reduction, though no short-term improvements in health status. ${ }^{26}$ The Mexican program, however, was designed for rigorous evaluation, in part because it grew out of a systematic nutrition planning process in Mexico which utilizes research undertaken specifically for policy purposes. ${ }^{27}$ 
Originally implemented in 1998-1999, with a delayed-implementation subpopulation serving as a control, the program includes the distribution of a micronutrient-fortified food supplement designed to meet the needs of infants 6-23 months of age, required participation in school for school-aged children, use of preventive healthcare services, and health education delivered through community-based clinics. The effects of the program have been shown to be positive based on indicators such as growth of infants, anemia prevalence, preventive health service utilization, and interestingly, functional measures in older adult members of participating households..$^{28}$

Altogether, the design and implementation of integrated approaches to nutritional improvement, including micronutrient malnutrition, requires large-scale planning and policy development but together with fortification of staple foods and targeted supplementation programs, may hold the greatest potential for long-term progress.

\section{MONITORING AND SURVEILLANCE}

Interventions require evaluation, both to assess progress and to identify any adverse effects. In the absence of randomized controlled trials, it is often necessary to rely on small-scale studies on non-representative samples to infer impacts. Many countries have recognized the need for food consumption and/or nutritional status data on representative samples from their populations, and there are many examples of cross-sectional surveys (which all too often do not get into the literature). It took the United States many years to come to the conclusion that the National Health and Nutrition Examination Survey (NHANES) would be most useful if maintained on a continuing basis (rather than requiring new funding and development of new infrastructure at infrequent intervals), and that integration of the former national food consumption survey activities into the survey would improve efficiency and utility. The NHANES data are freely available (see the homepage at: http://cdc.gov/nchs/nhanes.htm) and more or less continuously updated, forming a resource for both research and monitoring.

\section{SUMMARY AND CONCLUSION}

Optimizing the nutritional status of the population is one of the fundamental responsibilities of public health authorities as well as clinical care providers. Extensive experience with food fortification makes it one of the primary successful methods of intervention, but specific targeted risk group programs 
are also crucial to individual and population health. Education, cash and food entitlement programs are also appropriate in a multidimensional approach to food security and optimizing nutritional status, with monitoring as an essential element to evaluate needs and progress.

Conflicts of interest: None declared.

\section{REFERENCES}

1. Lopez AD, Mathers CD, Ezzati M, Jamison DT, Murray CJL, editors. Global burden of disease and risk factors. Washington (DC): World Bank Publications; 2006.

2. Jamison DT, Mosley WH, Measham AR, Bobadilla JL, editors. Disease control priorities in developing countries. Oxford: Oxford University Press; 1993.

3. TH Tulchinsky. Micronutrient deficiency conditions: global health issues. Public Health Reviews 2010;32:243-255.

4. Bhutta ZA, Ahmed T, Black RE, Cousens S, Dewey K, Giugliani E, et al. for the Maternal and Child Undernutrition Study Group. What works? Interventions for maternal and child undernutrition and survival. Lancet. 2008;371:417-40.

5. Contento I, Balch GI, Bronner YL et al. The effectiveness of nutrition education and implications for nutrition education policy, programs and research: a review of research. J Nutr Educ. 1995;27:279-83.

6. Szymlek-Gay EA, Ferguson EL, Heath AL, Gray AR, Gibson RS. Food-based strategies improve iron status in toddlers: a randomized controlled trial 12 . Am J Clin Nutr. 2009;90:1541-51.

7. Gibson RS, Anderson VP. A review of interventions based on dietary diversification or modification strategies with the potential to enhance intakes of total and absorbable zinc. Food Nutr Bull. 2009;30 (1Suppl):S108-43.

8. Centers for Disease Control and Prevention. Achievements in public health, 19001999: Safer and healthier foods. MMWR Morb Mort Wkly Rep. 1999;48 (40):905-913.

9. Food and Agriculture Organization of the United Nations. Hunger. Available from URL: http://www.fao.org/hunger/en (Accessed 28 December, 2009).

10. Alderman H, Linnemayr S. Anemia in low-income countries is unlikely to be addressed by economic development without additional programs. Food Nutr Bull. 2009;30:265-9.

11. Shankar AV, Asrilla Z, Kadha JK, Sebayang S, Apriatni M, Sulastri A, et al. on behalf of the SUMMIT Study Group. Programmatic effects of a large-scale multiple-micronutrient supplementation trial in Indonesia: Using community facilitators as intermediaries for behavior change. Food Nutr Bull. 2009;30: S207-14.

12. Rivera JA, Shamah T, Villalpando S, Monterrubio E. Effectiveness of a largescale iron-fortified milk distribution program on anemia and iron deficiency in low-income young children in Mexico. Am J Clin Nutr. 2010;91:431-8. 
13. Oakley GP. Folic acid and vitamin B12 fortification of flour: a global basic food security requirement. Public Health Reviews 2010;32:284-295.

14. Allen L, de Benoist B, Dary O, Hurrell R (editors). Guidelines on food fortification with micronutrients. Geneva: World Health Organization and Food and Agricultural Organization of the United Nations; 2006. Available from URL: http://www.who.int/nutrition/publications/guide_food_fortification_ micronutrients.pdf (Accessed 7 April, 2010).

15. Adu-Afarwuah S, Lartey A, Brown KH, Zlotkin S, Briend A, Dewey KG. Randomized comparison of 3 types of micronutrient supplements for home fortification of complementary foods in Ghana: effects on growth and motor development. Am J Clin Nutr. 2007:86:412-20.

16. Vinodkumar M, Rajagopalan S. Efficacy of fortification of school meals with ferrous glycine phosphate and riboflavin against anemia and angular stomatitis in schoolchildren. Food Nutr Bull. 2009;30:260-4.

17. Ten Year Strategy to Reduce Vitamin and Mineral Deficiencies, Maternal, Infant and Young Child Nutrition Working Group: Formulation Subgroup. Formulations for fortified complementary foods and supplements: Review of successful products for improving the nutritional status of infants and young children. Food Nutr Bull. 2009;30:S239-55.

18. Zehner ER. Integrating maternal, infant and young child nutrition: Report on the Ten Year Strategy Infant and young Child Nutrition (IYCN) Working Group October 2008 workshop. Food Nutr Bull. 2009;30:S190-6.

19. Institute of Medicine. WIC Food Packages: Time for a Change. Washington (DC): National Academies Press; 2005. Available from URL: http://www. iom.edu/ /media/Files/Report\%20Files/2005/WIC-Food-Packages-Timefor-a-Change/wic8pagerwithtables.ashx (Accessed 6 April, 2010).

20. Owen AL, Owen GM. Twenty years of WIC: a review of some effects of the program. J Am Diet Assoc. 1997;97:777-82.

21. Black MM, Cutts DB, Frank DA, Geppert J, Skalicky A, Levenson S, et al. for Children's Sentinel Nutritional Assessment Program Study Group. Special supplemental nutrition program for women, infants and children participation and infants' growth and health: a multisite surveillance study. Pediatrics. 2004; 114:169-76.

22. Buescher PA, Horton SJ, Devaney BL, Roholt SJ, Lenihan AJ, Whitmire JT, et al. Child participation in WIC: Medicaid costs and use of health care services. Am J Public Health. 2003;93:145-50.

23. Jones G, Steketee RW, Black RE, Buttha ZA, Morris SS. How many child deaths can we prevent this year? Lancet. 2003;362:65-71.

24. Guyon AB, Quinn VJ, Hainsworth M, Ravonimanantsoa P, Ravelojoana V, Rambeloson Z, et al. Implementing an integrated nutrition package at large scale in Madagascar: The Essential Nutrition Actions framework. Food Nutr Bull. 2009;30:233-44.

25. Lagarde M, Haines A, Palmer N. The impact of conditional cash transfers on health outcomes and use of health services in low and middle income countries. Cochrane Database Syst Rev. 2009(4) CD008137. Available from URL: 
http://mrw.interscience.wiley.com/cochrane/clsysrev/articles/CD008137/pdf_ abstract_fs.html (Accessed 7 April, 2010).

26. Rivera CB, Currais Nunes L, Rungo P. The impact of conditional cash transfers on health status: the Brazilian Bolsa Familia Programme. Rev Esp Salud Publica. 2009;83:85-97. (article in Spanish).

27. Rivera JA. Improving nutrition in Mexico: The use of research for decision making. Nutr Rev. 2009:67:S62-5.

28. Rivera JA, Sotres-Alvarez D, Habicht JP, Shamah T, Villalpando S. Impact of the Mexican program for education, health and nutrition (Progresa) on rates of growth and anemia in infants and young children: a randomized effectiveness study. JAMA. 2004;291:2563-70. 